\title{
Diferenciación y desdiferenciación política en la modernidad y periferia de la sociedad moderna
}

\author{
Raúl ZaMORAno Farías*
}

\begin{abstract}
This paper describes and analyses the articulation relationships and logics between politics, economy and jurisprudence aming to stabilise the complex modern democracies, specially in the periphery of modernity. It is interesting to observe why cognitive and normative expectations are not successful in creating lasting political arrangements that facilitate the social and political evolution. In particular in Latinamerica, where the ideas of corporation and customer power are still preferred compared to institutionalised expectations. This leads us to question how democracy is possible in this periphery of modernity.
\end{abstract}

Keywords: modernity, periphery, complexity, politics, jurisprudency, dfferentiations, dedifferentiation, exclusion, inclusion, expectations.

\section{Resumen}

Este trabajo tiene por objetivo describir y analizar las relaciones y lógicas de articulación entre la política, la economía y el derecho al respecto de la estabilización de las complejas democracias modernas, fundamentalmente en la periferia de la modernidad. Interesa observar por qué las expectativas cognitivas y normativas (derecho) no logran acomodos políticos duraderos que faciliten la evolución sociopolítica en un escenario como el latinoamericano, donde siguen primando las corporaciones y el caudillismo clientelar, mas no las expectativas institucionalizadas, preguntándonos entonces cómo es posible la democracia en esta periferia de la modernidad.

Palabras clave: modernidad, periferia, complejidad, política, derecho, diferenciación, desdiferenciación, exclusión, inclusión, expectativas.

* Centro de Investigaciones Interdisciplinarias en Desarrollo Regional de la Universidad Autónoma de Tlaxcala. Correo-e: rzamorano61@yahoo.it 


\section{Introducción ${ }^{1}$}

El análisis y la observación en torno a la semántica de la democracia y su evolución en la sociedad moderna debe contemplar el relevante cambio del significado de lo político en el curso de las últimas décadas, recuperando una antigua discusión e instalándola en la complejidad de la sociedad contemporánea, desde una mirada que no desconoce su origen, sino que lo asume.

Al respecto, resulta particularmente interesante la reflexión acerca de las democracias en la periferia de la sociedad moderna y la relación siempre difícil con el sistema económico y con el derecho. En los sucesos vividos en estos últimos meses en $\mathrm{Ar}-$ gentina, se puede observar cómo la demanda que se hace al Estado es precisamente no permitir el funcionamiento de la economía como un subsistema autónomo y la pregunta que inevitablemente surge es cómo se puede hacer esto posible.

La democracia, en consecuencia, se usa para cubrir diferentes conceptos y modos de operación, mientras la teoría democrática sigue pensando al Estado como coincidente con la sociedad (casi como un sinónimo de ella) o, al menos, como su expresión válida, y se niega a confrontarse con versiones que dan cabida a una mayor complejidad de la sociedad y de sus subsistemas.

Precisamente, la reflexión teórica que considera la autorreferencia de los sistemas sociales, su determinismo estructural y la incapacidad demostrada para dejarse irritar por lo que no hace resonancia en sus estructuras conduce a sistemas que se atribuyen la prioridad. La democracia, entonces, aparece bajo un cariz diferente y sólo puede ser desacreditada políticamente. ${ }^{2}$ Pero, nuevamente el caso argentino y los temores que se vuelven a despertar de ingobernabilidad, de golpe de Estado, de acefalía, generan dudas difíciles de disipar al respecto.

\footnotetext{
${ }^{1}$ Este trabajo se apoya en la investigación conducente al grado de doctor en sociología jurídica que el autor desarrolló durante sus estudios en la Facultad de Jurisprudencia de la Universidad de Lecce (Italia, 1999-2002): Civilizzazione delle aspettative e democrazia nella periferia della società moderna, y en una investigación que desarrolla el autor en la Facultad de Ciencias Políticas y Sociales de la UNAM.

${ }^{2}$ Desde este punto de vista, el sistema social es de hecho concebido como un mecanismo de reducción de la complejidad del mundo a través de una delimitación de aquello que asume relevancia al interior del sistema. Es precisamente esta pluralidad de implicaciones y la totalidad de los eventos lo que imposibilita una percepción global del mundo.
} 


\section{Adversus modernus}

El despliegue de la modernidad conlleva acelerados procesos de diferenciación funcional que incrementan el dinamismo de la sociedad. A lo largo de la evolución este proceso ha advenido en un gradual aumento de diferenciación social que ha llevado a la constitución de sistemas parciales, pero también a una agudización de los fenómenos de disgregación, fragmentación, integración y exclusión.

Hablamos, en general, de diferenciación cuando un sistema se diferencia del propio entorno al trazar sus límites diferenciados, haciendo posible a éste observar que existen otros sistemas en el propio entorno. Por ejemplo, 'en el entorno de la sociedad existen sistemas psíquicos y sistemas orgánicos'. La diferenciación del entorno no depende del sistema, sin embargo asume formas particulares según las distinciones que orientan la observación del sistema. ${ }^{3}$ Ahora, la característica central de este proceso es que cada función que forma parte del esquema de diferenciación sirva a un solo sistema parcial de la sociedad. De otra manera esta forma de diferenciación no se realizaría y aunque, evolutivamente, se pudiese hablar de división del trabajo social, diferenciación de roles o de una multiplicidad de distinciones semánticas sería implausible afirmar una diferenciación funcional de este tipo, toda vez que el factor que posibilita operar esta diferenciación es la comunicación.

Si nos remontamos al tardo medioevo, esta forma de la diferenciación no se llevaba a cabo todavía. Había entonces diversos campos para la verdad, por ejemplo: la religión, la filosofía, la retórica; había también diversos sistemas monetarios, unos para el comercio local, otros para el comercio más lejano; había distintos regímenes políticos, en el plano del imperio, en el de los territorios de los Estados, en el de la Iglesia. Evidentemente, las relaciones entre estos diversos planos parciales de racionalidad funcional eran correspondientemente complicadas. Sin embargo, el orden social no dependía de esta situación; estaba garanti-

${ }^{3} \mathrm{Al}$ respecto véanse Baraldi (1996: 56-57) y Luhmann y De Giorgi (1996). La forma de diferenciación establece el modo en el que en el sistema global se realiza la relación entre los sistemas parciales; tiene relación con la diferencia entre sistemas, que son unos en el entorno de otros Luhmann y De Giorgi (1996: 58). La diferenciación funcional articula la sociedad con base en la división del trabajo, en diversos subsistemas con funciones específicas y complejas y de tal modo aumenta la complejidad social. Véanse Zolo (1997: 248) y Torres (1996: 66). El binomio sistema/entorno es una operación sustentada en una diferencia (Spencer-Brown, 1979). 
zado mediante estratificación, la cual se abandona gradualmente una vez que empiezan a aumentar las dificultades de coordinación de la sociedad. El paso hacia la diferenciación primaria por funciones se impuso así -frente al orden anterior- en el plano estructural y semántico, por el camino de la diferenciación y la constitución del Estado-nación, territorial y políticamente soberano (Luhmann, 2001: 1-5).

Soberanía que no sólo fue entendida como 'independencia' con respecto a otros poderes políticos, léase el imperio o la Iglesia, sino como la capacidad del Estado soberano para responder, en un territorio claramente delimitado, a todos los problemas y cuya solución exigía que el poder político quedara concentrado. Luhmann señala que en la temprana Edad Moderna se intenta introducir una combinación de universalidad y especificación como capacidad universal de autonomía en cada uno de los campos funcionales de los sistemas parciales de la sociedad. Esta fue la única manera de sobreponerse con medios políticos a guerras en torno a la verdad. Es decir, sobreponerse a las disputas violentas de las controversias provocadas por las preguntas cientificas o religiosas (Luhmann, 2001: 5).

Avanzando en el tiempo, ya en la segunda mitad del siglo XVIII, la semántica sociopolítica de Europa se revoluciona totalmente con el predominio del discurso ilustrado y con el imperativo de la razón, conservándose desde entonces casi sin cambios significativos, puesto que la instalación del Estado Social y el Estado de Bienestar -en los siglos XIX y Xx, respectivamente- serán las únicas recepciones realmente novedosas hasta finales de la centuria a excepción, claro está, de las guerras y la cotidiana carnicería que han caracterizado a los últimos cien años. ${ }^{4}$

Así, durante los dos últimos siglos, la modernidad y la sociedad han estado modeladas y orientadas por los principios de la Ilustración que a través de la cristalización de grandes objetivos, explícitos ya desde el Renacimiento, trazó el pensamiento iluminista, el cual promovió el Estado moderno que terminó de separar la política de las concepciones sacras, sobrepasando al absolutismo para colocar al pueblo como el sujeto por excelencia de

\footnotetext{
${ }^{4}$ El siglo xx fue el más sanguinario del que la historia tenga registro. Hubo pocos y breves periodos en los que no hubiera algún conflicto armado organizado en alguna parte y la guerra fue casi ininterrumpida (véase Hobsbawn, 2002).
} 
la política, reinaugurando, con la Revolución francesa, la historia del mundo. ${ }^{5}$

Precisamente esto nos lleva a considerar la cuestión de las diversas descripciones y formas en las cuales la sociedad moderna se ha construido y cómo también este proceso evolutivo ha aumentado la incertidumbre y un sentimiento de desamparo, cuyo origen radica en las lógicas de inclusión-exclusión intrínsecas a todo proceso de diferenciación. ${ }^{6}$

Situación que se torna más evidente y dramática en América Latina, donde el referente de la sociedad moderna, que en nuestro continente nunca se cristalizó plenamente, se ve afectado hoy por significativos cambios estructurales (desplazamiento a una economía terciaria y los diversos impactos que genera el advenir globalizador) y donde la reflexión sobre la política de la sociedad contemporánea continúa anclada en las preocupaciones por la totalidad, por las grandes construcciones sobre el mundo, pero no en las necesarias compensaciones que se generan en la simultaneidad y contingencia de las decisiones -o no decisiones- (complejidad) que este proceso de diferenciación y modernización desencadena. ${ }^{7}$

${ }^{5}$ Será a través de estas semánticas históricas que la sociedad se ha venido observando temporalmente y diferenciándose, en relación con su interior, para construir la diferencia con el entorno. Estas representaciones de la diferencia, que se sedimentan, han producido un patrimonio específico de la diferencia en cada fase de la evolución histórica (cristianos/paganos, nobles/plebeyos, capitalistas/proletarios, desarrollados/ subdesarrollados) (véase Zamorano, 2001).

${ }^{6}$ Sin embargo, el ideario político continúa orientado de acuerdo con el registro contenido en antiguos contratos sociales, sin preguntarse en qué medida la idea misma de contrato social -en el marco de una creciente descentralización de la acción política- puede ser vigente. Además, la misma distinción clásica, empleada en el marco de la sociología política, entre política/sociedad, que remite filosóficamente a la distinción entre espacio público de la vida política y la economía doméstica cuyo componente ético se afirma en una supuesta naturaleza humana orientada hacia su perfección en la comunidad política (vida buena), es ya inadecuada; e incluso, sociológicamente, el concepto filosófico de la koinonía politiké (como su moderna acepción: 'sociedad civil') resulta insuficiente. Generalmente y en su expresión más simple, esta distinción quiere señalar la distancia existente entre la gente que desempeña sus funciones en el ámbito de las organizaciones formales de la esfera política y el conjunto de individuos que se considera constituyen 'la sociedad' y se encuentran fuera de dichas organizaciones (y donde, frecuentemente, se termina apostando y tomando partido por los supuestos atributos normativos de 'la sociedad' a la cual se concibe como opuesta a una política caracterizada por su corruptibilidad). Pero en la actualidad no es posible entender la política como un sistema que se 'opone' o que 'controla' a la sociedad, sino como una distinción que acontece en ella como un nuevo sistema en un entorno. La política es, pues, siempre política de la sociedad, aun en la periferia de la sociedad moderna.

${ }^{7}$ Diferenciación funcional: factor característico de este proceso signado por campos autorreferidos que sólo asimilan elementos externos en tanto funcionales a su lógica específica (Véase Luhmann y de Giorgi, 1996). 
Ahora, ¿̇uáles son las limitaciones y dificultades conceptuales que se derivan de tal comprensión de la sociedad?

El peso de la tradición teórica, que nos había acostumbrado a observar la sociedad desde afuera, se torna problemático y ya a esta altura es imposible, pues se constata que fuera de la sociedad no hay nada. Si el operar de la sociedad tiene características específicas y todo lo que acontece lo hace simultáneamente, entonces la sociedad moderna opera siempre en el presente y a través de cada acontecimiento va produciendo la diferencia entre pasado-futuro, construyendo de esta forma estructuras de decisiones que siempre se toman en el único tiempo conocido, en la simultaneidad del tiempo presente. ${ }^{8}$ Además, con la modificación de las distancias geográficas (fronteras) y sociales (económicas) la política ya no opera sólo en el ámbito nacional sino global y local, poniendo en tensión el espacio clásico de la política: la soberanía nacional.

Esta aceleración, que ha afectado el trasfondo histórico de la conciencia, se diluye en proyecciones sin imágenes ni imaginarios quedando sólo el aquí y el ahora (se pierde el sentido del futuro), lo cual dificulta poner el presente en perspectiva afectando también al sistema político, que parece tener cada vez menos capacidad de satisfacer las demandas. ${ }^{9}$ Todo esto genera un aumento geométrico de la complejidad, lo cual evidentemente excluye también toda posibilidad de linealidad y toda deontología. ${ }^{10}$

De ahí que la única posibilidad es indicar a la sociedad como el resultado de sus propias operaciones que, a través de su operar, reproducen continuamente la diferencia con el entorno. Es decir, lo que es objeto de la observación se construye a través de esas operaciones y, precisamente, es este carácter determinado

\footnotetext{
${ }^{8}$ El mismo concepto de postmoderno es, en el mejor de los casos, desafortunado, pues ¿qué hay más allá de la sociedad moderna?

${ }^{9}$ La distinción entre pasado y futuro acontece siempre en el presente y tan sólo en el presente puede ser actual. Un interesante trabajo sobre el tema es el del historiador alemán Kosellek (1986).

${ }^{10}$ Recordemos que por muchas centurias las diversas organizaciones sociales funcionaron de manera aislada, es decir cerradas, pero ya desde el siglo xv, con la expansion europea tras el 'descubrimiento' de América, la sociedad deviene en un sistema mundial. (Wallerstein ha retomado esta idea de Marx: el sistema mundo tiene como soporte el nacimiento de la economía mundial). De allí que el fenómeno llamado globalización no es tan nuevo como suele pensarse. La estructura de la sociedad se fue caracterizando por mayores grados de complejidad, integración y autonomía (diferenciación) de sus sistemas y por la burocratización y especialización de la organización formal. Advenir evolutivo, el cual posibilita que en la moderna sociedad el sistema delimite sus fronteras respecto al entorno gracias a operaciones específicas que siempre consisten en comunicaciones
} 
por la continua producción de la diferencia y auto-observación el cual nos permite preguntarnos cómo se puede observar la moderna sociedad, y cómo es posible en ella la democracia. ${ }^{11}$

Actualmente, y en un mundo extremadamente complejo donde el margen en la tensión de la experiencia intencional y del actuar son también extremadamente reducidos, la superabundancia de posibilidades supera siempre aquello que somos capaces de elaborar a través de la acción y de la experiencia (Luhmann, 1991). Empero, esto significa y supone una condición de incertidumbre en lo que atañe a la realidad externa. Incertidumbre que se refiere a la superabundancia de posibilidades no actualizadas por la experiencia y al riesgo relativo a la actualización de una posibilidad entre muchas. A la primera condición podemos nominarla con el término complejidad y a la segunda con el de contingencia.

La complejidad viene así imponiendo la necesidad de elegir entre una pluralidad de opciones, ahí donde la contingencia hace evidente que aquella elección hubiera podido hacerse de otro modo, exponiendo al sistema al riesgo de la selección efectuada (véase Luhmann y De Giorgi, 1996: cap. v). En esta perspectiva teórica, los sistemas sociales desarrollan la función de reducir la complejidad del mundo, mediando entre la extrema indeterminación de éste y el escaso potencial de sentido de la experiencia y la acción. Los sistemas sociales atenúan, entonces, la dificultad propia de la complejidad del mundo, delimitando la selección de las posibilidades de la experiencia presentes en éste (véase Luhmann, 1973: 81, passim).

Pero un sistema no sólo reduce la complejidad del mundo, sino que, a través de la selección de las posibilidades dotadas de sentido, crea una demarcación con su entorno. ${ }^{12}$

${ }^{11}$ La ontología clásica no puede dar cuenta de estos fenómenos porque la propia estructura de la sociedad moderna la ha hecho añicos. La contingencia, donde todo es improbable pero posible de actualizarse, es la introducción de la nada histórica, pues siempre puede ser de otra manera (no hay teleología). La actualización de la nada es el observador (la operación que realiza), el tercero excluido (por ejemplo, en la pintura la perspectiva del observador no aparece en el cuadro, pero es la que hace la diferencia). Interesantes resultan, en tal sentido, los aportes de la teoría sociológica de los sistemas sociales, como herramienta teórica capaz de escapar a dichas limitaciones y dificultades. Luhmann postula la idea de que el sistema se distingue del entorno con base, exclusivamente, en operaciones comunicativas (Luhmann, 1991 y 1996).

${ }^{12}$ Se define, entonces, una diferencia que es la diferencia sistema/entorno, en cuya base la selectividad del sistema hará posible en su interior sólo aquellas acciones que sean relevantes para él. Así, se produce una especificación de la complejidad del mundo, en donde los problemas son identificados como problemas del mantenimiento del(os) sistema(s). El concepto de complejidad significa que el mundo ofrece al hombre 


\section{Complejidad y política de la sociedad moderna}

Resulta del todo evidente que en una realidad social, donde se incrementa la diferenciación y el dinamismo, se generen distorsiones y desencuentros (entre expectativas y normas) que van minando la credibilidad y confianza entre las élites gobernantes y los ciudadanos, pero también, como se ha indicado, que se agudicen gradualmente los fenómenos de exclusión y disgregación social, fundamentalmente en las periferias de la sociedad moderna. ${ }^{13}$

Así, nuestra periferia latinoamericana del siglo Xxi, aun cuando no es la misma, vuelve a encontrarse con sus viejos problemas (véase Leal, 1996). Tras diez años, caracterizados por la globalización y el neoliberalismo, comienzan a emerger los mismos problemas del siglo xx como si se tratara de una enfermedad endémica. Los noventa, que sucedieron a la denominada 'década perdida' por el arrastre de la deuda externa, se estrellan con el albor del nuevo milenio y descubren con desengaño que las políticas económicas ejecutadas no lograron suavizar las miserias. Quizá la región sea más rica que antes al observar las estadísticas de su producto interno, pero este argumento no resuelve de todos modos la iniquidad, el alto desempleo, la inseguridad so-

una cantidad prácticamente ilimitada de posibilidades de experiencia y de acción a la cual corresponde una capacidad muy reducida de percibir, elaborar informaciones y actuar. La complejidad, así entendida, es un exceso de las posibilidades del mundo; es decir, la diferencia entre el número de las posibilidades potenciales y el número de las mismas actualizadas. En este sentido, la complejidad significa necesidad de selección. Más específicamente, por complejidad se entiende: $i$ ) el número y la variedad de los elementos de un sistema; ii) la extensión y la incidencia de las relaciones de interdependencia entre los elementos de un sistema y iii) la variabilidad en el tiempo de los elementos y sus relaciones (véase Zolo, 1997: 245-246).

${ }^{13}$ Entendemos por periferia de la sociedad moderna el tipo de orden social cuya característica central es la estratificación (es decir, sus formas operativas se encuentran más en el campo de la organización) y donde, evidentemente, su sentido de operación tiende a la estratificación social y no a la diferenciación. En otras palabras, como una diferencia socioestructural producida por la modernidad de parte de sí misma y respecto de sí misma. La modernidad construye una imagen de sí misma y lo que no entra en esta imagen se considera como su periferia, lo cual no significa, en ninguno de los casos, que en este tipo de diferenciación la periferia sea menos importante que el centro. Ello equivaldría a aprehender esta forma de diferenciación de manera falsa, según el modelo de relación por rangos jerárquicos. Véase Luhmann (1998) y Luhmann y De Giorgi (1996). 
cial, la precariedad laboral, la pobreza ${ }^{14} \mathrm{y}$, menos aún, la frágil institucionalidad y civilización de las expectativas. ${ }^{15}$

Ahora, si todo orden social diferenciado crea una civilización de expectativas correlativas que posibilitan, precisamente, ese orden social diferenciado, el punto fundamental entonces es un sentido de objetivación de la indiferencia ante un orden social diferenciado, de lo contrario lo que hace astillas ese orden diferenciado es el corporativismo estatificado, el cual no puede, ni tiene la función, de representar a toda la sociedad. Lo que hay tras esto es un proceso que va generando sus propios subproductos que se institucionalizan (tal como para Norbert Elías), pero este procesualismo se opone al representacionismo, pues las tareas sociales son una construcción emergente (Hegel) y no representaciones trascendentales (Kant). ${ }^{16}$

Sin embargo, de cara a estos procesos, el sistema político en el continente pareciera haber perdido capacidad de control sobre las diversas expectativas y fases que porta la modernidad, caracterizándose más bien por su retraso en las formas de hacer y pensar la cuestión política y por las posiciones tradicionales y estatistas de las élites (donde no hay una idea clara del nuevo papel y las restricciones que abre el proceso de modernización). Es como si la política no tuviese tiempo para observar y organi-

${ }^{14}$ Tras una década de plena globalización, la región comienza a enfrentarse con sus problemas endémicos: iniquidad, pobreza, falta de oportunidades, a los que suma el desengaño en sus gobernantes. La respuesta desde los centros de poder es de más dureza, a la vez que el gran capital, que había convertido a América Latina en un buen y rentable mercado, inicia su repliegue (Véase Walder, 2002).

${ }^{15}$ Cuando el orden social introduce una comunicación, un pliegue de objetividad del comportamiento humano, al desvincular la comunicación de todo compromiso inmediato, de toda valoración metafísica, civiliza las expectativas abriendo toda una franja de evolución (cambio) social diferenciada que se 'objetiviza' en una norma. Esto supone la indiferencia social de los individuos frente a ese orden social. Es decir, presupone una suerte de despersonalización de lo personalizado (paradojalmente personalizado a través de la civilización de $x$ expectativa), creando el orden de la indiferencia característico de la modernidad (los derechos del hombre o las garantías individuales en el Estado de derecho). El proceso de diferenciación funcional es, en última instancia, una contingencia domesticada, donde los predicados crean al sujeto, son para el sujeto (Hegel), sin principios ni articulación jerárquica (es una filosofía de la historia postkantiana, en donde no se busca la justificación a partir de un juez racional o metafísico). Este orden social diferenciado, al que hemos llegado, es un orden que se maneja en el ámbito de las expectativas (horizonte simbólico).

${ }^{16}$ Para Hegel hay una unidad operativa indeterminada (nada) por la que se llega a una unidad determinada en movimiento (cuando la razón se despliega), mientras que para Kant hay una unidad trascendental. Recordemos que para Kant la realidad se representa (no se construye). En Luhmann la diferencia última está en la unidad de la diferencia como fundamento; el fundamento para la sociología es una posición factual, pues el hombre es un animal de distinciones antes que un animal racional (véase Luhmann, 2001). 
zar secuencialmente sus propias operaciones. Por lo tanto, no es de extrañar que a escala mundial y continental se viva un fenómeno de desafección y, también, un cierto malestar por la cuestión política.

Hoy es un lugar común declarar que las sociedades contemporáneas más desarrolladas han fundado sus logros en la creciente civilización de las expectativas y la consecuente ampliación de los derechos individuales, en la generalización de las formas democráticas de gobierno, en la asignación de recursos sobre la base del mercado, en el conocimiento científico y tecnológico y en la instrumentalización de los vínculos sociales por medio de organizaciones formales; lo cual es cierto, toda vez que dicho proceso ha estado asociado con una acentuada diferenciación en sistemas parciales que vienen desplegándose sin reconocer restricciones, salvo las contenidas en sus propias estructuras y que hacen referencia a operaciones autorreferenciales (Luhmann, 1991).

Sin embargo, el impacto y las transformaciones de las revoluciones de fines del siglo XVIII y principios del XIX en Europa y Estados Unidos no arribaron a estas costas; por el contrario, al parecer le impusieron a América Latina una pesada estructura de gobierno que le ha impedido transitar hacia la evolución política y social. Es como si la gran ola revolucionaria que barrió al mundo atlántico hubiera depositado un conjunto de preceptos practicables sólo en Europa y Estados Unidos, e instituciones defectuosas en el resto de las repúblicas latinoamericanas, porque a diferencia de las sociedades europeas, cuyo proceso de diferenciación funcional resultó en un patrón de organización social de tipo policéntrico, donde los sistemas sociales operan descentralizados y de modo autónomo aunque acoplado, las sociedades latinoamericanas se han caracterizado por estar estructuradas en torno a un sistema centralizado, dominante y autoritario.

En tal dirección, y tras de la discusión sobre la modernidad y la política, actualmente en América Latina se reinstala otra discusión histórica que acompaña su desarrollo y evolución: la modernización. En el continente, la instancia privilegiada de coordinación sociopolítica fue y ha sido el Estado; recordemos, como ha señalado Whitehead (1998), que entre 1930 y principios de los años ochenta, el gran Estado de compromiso social ('bienestar') centralizado se volvió la norma en prácticamente toda la región a partir del modelo ideado por la Constitución 
mexicana de 1917. Ello, en un escenario donde los diferentes sectores sociales exhibieron históricamente una menor propensión a la moderación y la prudencia política en el planteamiento de sus demandas y, donde también las élites dirigentes mostraron más descarnadamente su irresponsable demagogia avaladas por las instituciones representativas, que operativamente han sido incapaces de refrendar y canalizar las expectativas desbordadas de una tumultuosa ciudadanía. ${ }^{17}$

Al respecto, por ejemplo, amparados por los diseños constitucionales los nuevos derechos se han convertido, por lo general, en la fachada de las autoridades centrales para comprar lealtades, cuestión por demás característica en el continente, ya que, también históricamente, el fracaso de la ley frente a las estructuras autoritarias puede explicarse, en parte, por la ausencia de movilización social en favor de las reformas y por la instrumentalización de ésta por las clases en el poder. Como señala Langley, históricamente las ideas liberales han sido sólo compartidas por las élites, mientras las masas, al tiempo que eran movilizadas en favor de la independencia, tenían que ser controladas para evitar que las nuevas repúblicas se salieran de control (véase Langley, 1996).

Este tipo de coordinación social, que se fundó en la existencia de una administración pública, un Estado de derecho y en una clásica idea del Estado influyente, se apoyó sobre una cierta concepción de soberanía, toda vez que suponía una clara diferenciación entre sociedad y Estado, donde la centralización del poder en el Estado como instancia legítima de dominación en tanto autoridad reconocida, operaría como vértice de la sociedad. ${ }^{18}$ Así se fueron configurando e interpenetrando lógicas del quehacer político que remitían a ciertas instituciones comunes en el área: el paradigma de la planificación racional, cuya máxima expresión fue el Estado desarrollista, entre los años cuarenta y sesenta del siglo pasado.

${ }^{17}$ El Estado, como se ha señalado, fungió como el motor de la economía y la industrialización. El esquematismo tradición/modernidad es abandonado y el discurso en adelante no será ni heroico ni épico, pues ya no hay tránsito a algo distinto, sino lo único posible es lo que hay, situación marcada por el resurgimiento de ejes y temas de las etapas precedentes (modernización, desarrollismo, dependencia). Se da una vuelta a ideas abstractas y generalizantes de aplicación universal, una especie de 'neo-modernismo' económico donde el concepto de democracia vuelve a ser central.

${ }^{18}$ Soberanía en el doble sentido, como garantía de la unidad nacional respecto al sistema internacional (externa) y como garante de la cohesión interna, donde el Estado articula la vida social mediante la coordinación política, vértice de la sociedad. 
Esta intervención racionalizadora del Estado presupone -en el lenguaje de Lechner (1997) - una realidad social de escasa complejidad para que las normas de reciprocidad sean aplicables; es decir, la suposición de un sistema compuesto de acciones recíprocas entre individuos en una cadena de causalidad simple y una ejecución obediente de las medidas es una conceptualización que descansa en la convicción de que las metas, los medios y criterios están claramente determinados y priorizados, y que la acción individual se agrega sin fisuras tras la consecución de las metas y fines colectivos (Lechner, 1997: 9 y ss.). Mas dicha concepción de la coordinación total de la sociedad a través de la planificación integral se desmoronó, porque ya no puede funcionar más como narrativa de la historia (meta-discurso, como referencia existencial a su propio tiempo). Las esperanzas depositadas en la planificación política y en su capacidad predictiva colapsa, constatándose que la modernización no concluye en la región, ni con la revolución ni con el mentado desarrollo. ${ }^{19}$

Precisamente, en la actualidad, las limitaciones de las distinciones conceptuales clásicas como soberanía, politica y sociedad crean dificultades porque con estos conceptos tan reificados resulta difícil, cuando no implausible, entender la dinámica política de la sociedad moderna. Sumado a esto, la concepción de orden social centralizado articula un tipo de estructuración de sistemas funcionales caracterizado por precarios niveles de autonomía funcional y operativa, en el cual sistemas así diferenciados bloquean o ponen obstáculos al despliegue autorreferencial de lógicas parciales en vías de diferenciación.

Como se indicó, en el vértice institucional de esta particular forma de estructuración se ha situado el sistema político, y en su referente descriptivo, el Estado. Mascareño (2001) señala que desde el origen de las Repúblicas ha sido la política, incluso con prescindencia de la legitimidad jurídica, el sistema funcional que ha definido los lineamientos para el desarrollo de otras esferas. Claros ejemplos de dicha indiferenciación son la historia de estados de excepción en América Latina (indiferenciación políticaderecho). En el ámbito territorial este carácter concéntrico adquirió la forma de centralización. Especialmente los campos

${ }^{19}$ A pesar de tan dramática constatación, aún hoy se sigue apelando al mentado tema del 'desarrollo'. Sin ir más lejos, en la reciente Conferencia Mundial Para el Financiamiento de la ONU (México, Monterrey 18-22 de marzo de 2002), los temas centrales fueron las llamadas 'cuotas de desarrollo' y el 'consenso para el desarrollo'. 
educativo, cultural y económico sufrieron sus consecuencias durante gran parte del siglo XX.

Además, en nuestros países, históricamente el poder -en manos de una élite descendiente en su mayoría del colonialismo imperial- se articuló en función de generar el Estado-nación (homogeneizar el lenguaje, ciertos valores y concepciones, símbolos y patrones culturales) y las instituciones de la sociedad. De allí la referencia histórica de la sociedad civil al Estado y luego al sistema de partidos, como legítimo intermediario entre ambos, que va instituyendo formas en que el sistema político (particularmente en la fuerte institucionalidad chilena) garantiza la dominación social. Una eficiencia de la dominación que, haciéndose fuerte en el Estado, termina por subsumir a la organización social y ahogar a la llamada 'sociedad civil' (corporativismo de Estado: Argentina, México). ${ }^{20}$

En el campo cultural, el imperativo de la transformación de la barbarie en civilización, que definió la acción estatal por medio de la noción de progreso durante gran parte del siglo XIX, se transformó en el xx en la unidad en torno a la idea de desarrollo, con lo que las diferencias culturales locales sólo fueron aceptables en la medida en que no intervinieran con aquellos objetivos mayores. En el campo económico, la centralización se tradujo en industrialización urbana y en el manejo planificado y guiado desde el Estado del proceso de sustitución de importaciones (indiferenciación política-economía) (Véase Mascareño, 2001).

Así, el desarrollo se transformó en una evolución controlada jerárquicamente desde un sistema funcional situado en la cúspide de la sociedad: el sistema político. Todo lo cual ha configurado una particular forma de 'diferenciación/desdiferenciación' que coexiste al interior de los órdenes sociales de la región, generando definiciones homogéneas y abarcantes que obstaculizan el despliegue y consolidación de la autonomía sistémica, toda vez que los acoplamientos se transforman en procesos de desdiferenciación que al ser reemplazados por sustitutos funcionales y fórmulas de autoentendimiento (relaciones clientelares, caudillismo), dificultan el despliegue de la especialización de funciones y de la operatividad democrática.

\footnotetext{
${ }^{20}$ Dicho sea de paso, los aduladores de la república americana olvidan generalmente que los padres fundadores establecieron la Constitución con el propósito de luchar en contra de los movimientos sociales subversivos que se manifestaban en la época (Castoriadis, 2001).
} 


\section{La ley se acata, pero no se obedece}

Siguiendo esta perspectiva, en la actualidad, todavía algunos políticos y cientistas sociales que confían en una supuesta racionalidad y previsibilidad de las decisiones políticas, piensan que es plausible orientar la economía, la educación, la ciencia y el derecho, en fin, el conjunto de la sociedad y del mundo, a partir de las operaciones del sistema político y del Estado. ${ }^{21}$ Situación que se agrava, cuando no se torna crítica, por el bajo grado de institucionalización de las expectativas (cognitivas-normativas) y por la especial forma histórica de hacer política en el continente: el movimentismo ${ }^{22}$ o caudillismo, donde todo el desarrollo y consecución de objetivos político-sociales y económicos se ha dado a través de la lucha de movimientos, situación que a menudo fue interrumpida por la acción de golpes militares. ${ }^{23}$

Estos movimientos pueden ser definidos como formas de acción colectiva que establecen relaciones verticales entre un líder carismático y una masa que sigue la presencia e ideología de ese líder, los cuales tienen características particularmente esencialistas (centradas en valores) y cuyas articulaciones generan una fuerte identificación horizontal entre los sujetos miembros, todo lo cual define la acción política en una lógica 'amigo' (los movimentis-

${ }^{21}$ Esto queda de manifiesto en el recurrente llamado al retorno a la polis, a la política como vértice de la sociedad. Un caso ejemplar es el del sociólogo chileno Manuel Antonio Garretón: "Estamos frente al mismo problema que se vivió a principios del siglo XIX; cómo construir sociedades polis y controlar el poder fáctico [...] Frente al fracaso de la matriz neoliberal que homologaba mercado y sociedad, hay que fortalecer al Estado, a la sociedad civil y a sus organizaciones". Seminario Internacional: Gobernabilidad y procesos sociales en América latina, Universidad Iberoamericana, 26, 27 y 28 de octubre, México 2000.

${ }_{22}$ Que surge principalmente con la crisis del estado oligárquico (década de los años 30), e intentan presentar un proyecto político alternativo: institucionalización no pluralista, fusión entre el Estado, la política y la sociedad, por ejemplo México (véase Alberti, 1997). En Asia y Latinoamérica la "evolución política se caracterizó por crecientes conflictos étnicos y clasistas, repetidos motines y violencia popular, frecuentes golpes de Estado militares, predominio de dirigentes personalistas inestables que a menudo adoptan desastrosas políticas económicas y sociales, una amplia y flagrante corrupción de ministros y empleados públicos, una violación arbitraria de los derechos y libertades de los ciudadanos, niveles decrecientes de eficacia y capacidad burocráticas, una difundida alineación de los grupos políticos urbanos, la pérdida de autoridad de legislaturas y tribunales, y la fragmentación (y a veces desintegración total) de partidos políticos con amplias bases de afiliados" Huntington (1972), véase también Lomnitz (1994).

${ }^{23}$ El péndulo entre la acción de los movimientos y la reacción de los militares, que emergen para terminar de una vez y para siempre con 'esta' situación, termina por lo general reproduciendo y profundizando una marcada orientación antiinstitucional (Alberti, 1997). 
tas) y 'enemigo' (los no movimentistas) determinando así el campo político. ${ }^{24}$

La conjugación de dichos factores, aunque matizados, son centrales en la constitución y articulación de la cultura política en las sociedades latinoamericanas de fin de siglo y marcan la lógica orientadora de las 'nuevas' democracias, donde ésta sigue siendo un problema porque algunos aspectos institucionales de la vida sociopolítica son deficientes, ya que, como se indicó, conservan las características típicas de movimentismo y de la desdiferenciación funcional (corporativismo). ${ }^{25}$

Esto genera que la relación entre política y derecho también se torne crítica pues, y más allá de la diferenciación funcional y operativa que suponen como subsistemas, al operar funcionalmente diferenciados éstos se vinculan recíprocamente a través de sustantivas prestaciones operativas, toda vez que el sistema del derecho ofrece al sistema político prestaciones fundamentales en cuanto a la legitimidad de las decisiones políticas y de la operativización de las premisas para el uso y aplicación del monopolio estatal de la violencia, mientras que la política ofrece al sistema jurídico las premisas decisorias en forma de ley. Ahora, si el sistema político es el sistema social por excelencia que tiene la capacidad de integrar sobre la base de una selección tomada (elección), su función no es otra que coordinar en decisiones colectivas vinculantes tanto a quienes adoptan las decisiones como a quienes son objeto de ellas. Pero allí requiere necesariamente del derecho como canal operativo que funcionaliza y hace operativas dichas decisiones, como también las prestaciones políticas ocurren cuando se precisa de decisiones vinculantes en otros sistemas funcionales.

Pero, como señala Fernandes Campilongo (2000: 42-43), sin autonomía funcional, la representación política y el derecho pier-

${ }^{24}$ Estilo de hacer y ser de la política; gobierno por decretismo, situaciones de violencia y marginalidad, tensiones entre la representación política y la actuación del Estado, exclusión, etcétera. Exponentes paradigmáticos de esta caracterización quedan representados por los populismos latinoamericanos clásicos: G. Vargas en Brasil y J. D. Perón en Argentina.

${ }^{25}$ Por ejemplo, en el Perú, donde los gobiernos de transición o nuevas democracias, han seguido los derroteros históricos en su forma de entender y hacer política, es decir, han reavivado la lógica movimentista de corte esencialista (Movimiento Cambio 90 de Fujimori). Ahí volvemos a ver la figura del líder carismático que guía a las masas en un escenario que, evidentemente, dista mucho del contexto donde se generaron los populismos clásicos. No pretendo sostener, como algunos suponen, que estamos frente a una suerte de neo-populismo, pues eso sería un anacronismo y un error político. Lo importante es constatar que se evidencian algunos fenómenos recurrentes en la historia política del continente, que es importante tener presentes a la hora del análisis. 
den su capacidad de garantizar procedimientos que mantengan abiertas y acrecienten las posibilidades de elección, variación y construcción de alternativas. Reconociendo que la función política no puede todo, puesto que es mucho menos capaz de transformar los grandes ideales en realidad, mas sin ella, se pierde una pieza fundamental para el mantenimiento de la democracia. De lo contrario, las formas de auto-entendimiento sólo refuerzan la ya frágil institucionalización en el continente.

El problema, entonces, es que en América Latina existe un enorme abismo entre expectativa cognitiva y norma, mientras que, por ejemplo, en las democracias consolidadas hay una concordancia razonable entre conducta y ley. Esta situación se ve agravada por las particularidades del desarrollo histórico del continente, donde el proceso de aprendizaje normativo ha sido permanentemente bloqueado a través del cierre de los espacios de discusión pública y el mantenimiento de dependencias personales y colectivas respecto del Estado y los agentes económicos. Este bajo nivel en la construcción institucional está íntimamente ligado a las formas asumidas en el proceso histórico de autoconstrucción de las sociedades civiles, especialmente por la erosión de los acuerdos legales constitucionales, consecuencia de prácticas y formas populistas de coordinación social.

Aunque en la actualidad la democracia goce de una amplía posibilidad en la región, se percibe un descontento en relación con su funcionamiento, ya que una cosa es tener 'democracia' y otra gobernar democráticamente al nivel de las instituciones, del sistema de partidos, del poder judicial o legislativo. ${ }^{26}$ Ello porque junto al impulso democrático prevalecen fuertes limitaciones político-constitucionales heredadas de la época colonial, y que han sobrevivido desde el caótico constitucionalismo del siglo XIX, hasta el reciente pasado autoritario. Limitaciones que plantean interesantes preguntas sobre la forma como operan estas democracias y cómo son posibles. ${ }^{27}$

En tal sentido, uno de los aspectos más críticos está dado por lo excesivamente integrado de nuestras sociedades; es decir, por

${ }^{26}$ Situación que ha quedado claramente demostrada por el grado de desconfianza y apatía en una sociedad como la chilena, según los respectivos informes sobre desarrollo humano del PNud (Santiago, Chile 1997, 2000).

${ }^{27}$ Por ejemplo, los militares no han sido llamados a juicio por sus violaciones a los derechos humanos y siguen conviviendo con la democracia y atentando contra los derechos humanos en toda la región y no sólo eso, las más de las veces actuando como el poder detrás del trono. Constituyéndose, a fin de cuentas, en poderes fácticos que en la práctica constituyen un 'Estado' dentro del Estado. 
el bajo procesamiento de sentido diverso (no hay pluralidad de lenguajes), y por la forma en que se ejerce el poder ejecutivo y la fragilidad del derecho para contenerlo. Por ejemplo, en la región resulta una característica general que la institución presidencial haya derivado en un presidencialismo excesivo, casi obsceno. Como señala Sartori (1996), bajo la intricada jurisprudencia y normatividad, el control del Ejecutivo ha sido tomado por presidentes que no lo eran en el sentido republicano de la palabra, sino émulos del absolutismo que acababan por desconocer la propia institución, la cual además no tiene el contrapeso necesario para limitar su poder. De estos excesos han derivado las diversas subespecies del presidencialismo criollo: el sátrapa, el caudillo o pretor, el patriarca, el cacique y el amo de estancia (Loveman, 1993). ${ }^{28}$

Además, si a lo anterior sumamos el hecho de que virtualmente todas las constituciones de la región contienen cláusulas para crear regímenes de excepción a través de los cuales los presidentes electos pueden actuar como dictadores constitucionales, dada la amplia definición del término 'emergencia' y dado los repetidos fracasos para crear balances institucionales al ejercicio de poder, los poderes de emergencia se constituyen, a fin de cuentas, en "la base jurídica de la dictadura y la tiranía", como indica Loveman (1993), o en el sustrato del clientelismo.

Esta forma de coordinación clientelar (que en la actualidad ha derivado en pretorianismo civil $)^{29}$ ha sido una de las prácticas que más han dañado a las democracias de la región, obstaculi-

${ }^{28}$ El caso chileno resulta casi kafkiano, a la fecha de facto se vive un gobierno cívico-militar porque ello quedó consagrado en la Constitución de 1980. El discurso de Chacarillas en 1977 explicitó esa Constitución muy claramente, señalando que los garantes de la institucionalidad son los militares, aunque el gobierno lo ejerzan los civiles. El discurso de Chacarillas no habla de transición sino de consolidación. En el resto del continente la situación no es muy diversa. En Argentina, por ejemplo, bajo el gobierno peronista de C. Menem, el Poder Judicial usó toda su autoridad para fortalecer la institución presidencial y debilitar a otros actores que 'amenazaran' la acción del Ejecutivo. Algunos años atrás, en Perú, los cambios constitucionales para reforzar la independencia del Poder Judicial fueron neutralizados por nuevas reformas del presidente A. Fujimori, mientras en Venezuela Hugo Chávez ha hecho lo imposible por neutralizar la Constitución de 1961. Por otro lado, en Guatemala, el Ejecutivo está en manos de un asesino confeso y en Bolivia Hugo Banzer, militar golpista de los años 70, ocupó constitucionalmente la presidencia de la República. En la práctica, el Estado en Latinoamérica pareciera ser prisionero de los militares, o de instituciones autonomizadas del Estado, o de diversos grupos civiles o instituciones religiosas o culturales, de gobiernos extranjeros o actores transnacionales (FMI-BM) o, como en algunos países de la región, de grupos ligados al narcotráfico.

${ }^{29}$ El pretorianismo, en acepción amplia, se define como la influencia política abusiva ejercida por algún grupo militar. En la actualidad, esta influencia perversa ya no es ejercida por los militares 'directamente', pero sí por sus émulos: los pretores civiles. 
zando la institucionalización real de las expectativas cognitivas y violentando las normas, formando coaliciones clientelares, casi mafiosas, que privatizando el bien común hacen implausible los beneficios de largo plazo para las inmensas minorías, promoviendo, a fin de cuentas, la inestabilidad política y social.

De allí que la exclusión, la pobreza y la falta de educación no sean fenómenos casuales o síntomas exclusivos de un bajo nivel de desarrollo económico, sino patrones endémicos en numerosos países de la región, producto de las lógicas de coordinación clientelar que han potenciado los grupos corporativos al interior de nuestras sociedades y que hacen imposible la vigilancia informada de las autoridades electorales por parte de muchos ciudadanos, pues no existen las instituciones operativas (del derecho, por ejemplo) o, en el mejor de los casos, éstas están representadas como anima. Es decir, figuran en los textos constitucionales, pero en la práctica se acatan mas no se obedecen. ${ }^{30}$

Hemos señalado que la característica sociopolítica más sobresaliente del devenir evolutivo en América Latina ha sido la precariedad de la institución cognitiva y los problemas para operativizar el derecho (normas). Inestabilidad y disfunción que no son el producto de una osificación institucional, sino de formas sobrentendidas, donde un tipo de mecanismo integrador, la integración normativa, viene siendo sustituido gradualmente por formas desintegradoras e inadecuadas de integración sistémica: el caudillismo clientelar.

El revival del caudillismo clientelar, que en su variante moderna Huntington denota como pretorianismo, es el resultado de una precaria y difícil evolución de la institucionalización política en relación con el desarrollo socioeconómico y la movilización social, toda vez que el desarrollo del orden social diferenciado supone un mayor simbolismo y una civilización de las expectativas, como presupuestos de la comunicación (y no en el sentido de introyección sobre el nivel de la conciencia, como suponía Norbert Elías), pero una sociedad, cuya lógica de coordinación dominante es el caudillismo clientelar o el mercado, aunque compleja y diferenciada, carece de estabilidad institucional. Más bien

${ }^{30}$ Durante la llamada Conquista de América, los conquistadores realizaban el siguiente ceremonial: cuando una ley en forma de edicto arribaba de ultramar, colocaban respetuosamente el texto escrito sobre su cabeza y repetían aquí la ley se acata pero no se obedece. 
es una sociedad donde la diferenciación e indiferenciación se presentan a un mismo tiempo. ${ }^{31}$

De allí que si la diferenciación social y la creciente movilización política no son seguidas por un incremento en la complejidad institucional, el resultado es un accionar político sin integración política. Es decir, una situación donde los actores sociales y políticos se movilizan sin una construcción simultánea de instituciones cognitivas y normativas capaces de articular y agregar sus demandas. Por lo tanto, aunque los diferentes sectores sociales busquen tematizar derechos, plasmándolos en el lenguaje de la ley, sin un poder judicial que funcione, esos derechos no pueden ser plenamente gozados, como queda de manifiesto en la historia reciente del continente. ${ }^{32}$

Por el contrario, en ausencia de mecanismos claros de mediación institucional, las fuerzas políticas y sociales se confrontan abiertamente unas contra otras, es decir, su politización no es canalizada por mecanismos institucionales sino que consiste en una guerra no mediada de todos contra todos. El resultado es que, en la práctica, las constituciones y el derecho se tornan 'flexibles' y las garantías constitucionales se hacen 'inciertas', o generalmente son manipuladas por minoritarios pero fuertes grupos de poder.

Sabemos que en las sociedades centrales los derechos fundamentales efectivamente se han institucionalizado y progresivamente extendido en sucesivas olas de juridificación política, económica y social, pues precisamente lo que distingue al sistema democrático de formas políticas o caudillescas es la praxis de acuerdos institucionales estables. Pero en los sistemas políticos de la periferia, las débiles instituciones se encuentran a merced de minoritarias fuerzas sociales que los 'colonizan' con el objetivo de obtener beneficios privados. Incluso, aun cuando éstas hayan adoptado formalmente dichas instituciones, no pasa de ser un gesto alegórico porque en la práctica son ignoradas o utilizadas funcionalmente como un nuevo instrumento de dominación (operativas sólo para algunos). Por ello, toda vez que se in-

${ }^{31}$ La civilización de las expectativas supone reglas básicas fundamentales referidas al individuo y al sistema, constituidas históricamente (institucionalización que señala el marco de referencia, las reglas del juego), y donde no se puede suponer el consenso (como lo hace Habermas). Son, más bien, las garantías individuales institucionalizadas y operando las que garantizan la civilización de las expectativas y la plausibilidad del consenso.

32 Sobre todo los actores subordinados, imposibilitados de informar instituciones normativas. Véase al respecto Zamorano (2001). 
crementa la participación política, que resulta del proceso de extensión de la ciudadanía (fundamentalmente social), ${ }^{33}$ el sistema democrático se tensiona y es incapaz de establecer mecanismos adecuados de agregación e intermediación de intereses, dejando la puerta abierta a reacciones autoritarias o manifestaciones caudillistas.

Por ejemplo, la fractura sociopolítica, consumada durante el gobierno de Eduardo Frei Montalva en Chile (1964-1970), al poner en marcha un programa que apuntaba a impulsar un modelo de acumulación cuya base era el gran capital financiero, perseguía legitimarse en los sectores populares a través de procesos crecientes de integración a su esquema de participación, pero sin el desarrollo institucional legitimante correlativo, ni modificaciones en la estructura social, principalmente lo relacionado con la distribución de la propiedad. ${ }^{34}$ Situación que elevó el grado de las tensiones sociales y la intensificación de las movilizaciones populares, estrechando el margen de maniobra y restringiendo las opciones políticas.

Gran parte de estos fenómenos de politización mediada por una baja institucionalidad se han explicado sobre la base interpretativa proveniente de algunos modelos de la cultura, de las estructuras simbólicas de la comunicación, o con recursos referidos a condiciones exteriores u objetivas como la dependencia económica, el aislamiento o la marginación pero, como es claro en el ejemplo anterior, cuando el aumento de la diferenciación

\footnotetext{
${ }^{33}$ Nos referimos a la ya clásica tipología de Marshall: Ciudadanía civil (siglo XVIII): derechos necesarios para la libertad individual, libertad de la persona, de expresión, pensamiento, fe, el derecho de propiedad, de contraer compromisos contractuales y el derecho a la justicia. Las instituciones asociadas a los derechos civiles (de manera más directa) son las cortes de justicia. Política (siglo XIX): derecho a participar en el ejercicio del poder político, como miembro de un cuerpo investido de autoridad política o como elector de sus miembros (las instituciones correspondientes y necesarias están dadas por el Parlamento y los consejos del gobierno local). Social: el rango que va desde el derecho a un mínimo bienestar económico y seguridad, hasta el derecho de vivir una vida 'civilizada', de acuerdo con los estándares predominantes en la sociedad (las instituciones que tienen conexión con estos derechos son el sistema educacional y los servicios sociales, característicos del siglo xx). Sobre esto véase Marshall y Bottomore (1998).

${ }^{34}$ La llamada promoción popular, política orientada al incremento de la integración y participación popular en la vida social a través de la instrumentación de organizaciones adecuadas que fortalecieran las orgánicas que los mismos pobladores habían generado. Sin embargo, se buscaba integrar a los sectores marginales a formas de participación clientelar. Guardando la irreducible distancia, de todo tipo, observamos que en Europa este proceso se caracterizó por una movilización que adoptó sin mayores traumas la forma de integración. Por ejemplo, en Inglaterra la progresiva incorporación de los sectores populares a la vida nacional fue acompañada por el surgimiento paralelo de una multiplicidad de instituciones y mecanismos integrativos legitimantes.
} 
societal y del pluralismo no viene acompañado por el establecimiento de una estructura institucional más densa, con la habilidad de establecer y manejar la complejidad social, las turbulencias y el poder corporativo ocupan de facto ese vacío. Vacío institucional que dificulta la operatividad democrática, en el sentido de una relación entre Estado, política y sociedad, lo cual termina nuevamente reproduciendo los modelos de exclusióninclusión movimentista: patrimonialismo, personalismo o caudillismo clientelar.

Al respecto, una ilustración paradigmática hasta el dramatismo del fenómeno de politización no mediada está dada por las dictaduras militares. Sabido es que a diferencia y en contraste con los pronunciamientos militares del pasado (los cuales eran una parte integral del juego caudillesco), las dictaduras militares que surgieron en las décadas de los sesenta y setenta a lo largo del mapa político latinoamericano se vieron a sí mismas como un intento fundacional para establecer las bases institucionales de un nuevo orden político que solucionaría el problema crónico del caudillismo, la 'politiquería' clientelar y el marxismo.

Las dictaduras militares, cuyas bases políticas estaban dadas por el modelo de la economía neoliberal y por la Doctrina de Seguridad Nacional, se comprometieron a restaurar el orden a través de la desactivación de la sociedad civil y la normalización de la economía. Su objetivo principal era contener la movilización popular radicalizada en la década anterior y el restablecimiento del orden a través de la fórmula del estado de emergencia. Era, según algunos teóricos, una respuesta a la descomposición del modelo capitalista, al resquebrajamiento y crisis del aparato estatal y la 'pérdida' de legitimidad del régimen político (Véanse Garretón, 1983; Lechner, 1995 y Moulian, 1997). Los militares se autoconcibieron como una solución al problema del caudillismo y además, como los únicos actores suprapolíticos que encarnaban aun los vilipendiados valores patrios.

Evidentemente el advenimiento de los militares al poder vino a transformar la función del Estado de compromiso en un Estado represivo y vigilante que eliminó el mercado político competitivo y el sistema tradicional de mediaciones políticas, subordinando el espacio público de la sociedad a las nuevas necesidades de control y disciplinamiento de la población, imponiendo nuevas formas de legitimación y obediencia.

En el contexto de la 'politiquería' clientelar, caracterizada por una politización no mediada, los militares se pensaron a sí mis- 
mos como el único actor capaz de actuar como un poder despolitizador neutral contra la politización. Sólo ellos estaban en posición de congregar a la población tras metas nacionales compartidas, dado que su tradicional desdén por la política los ubicaba como un poder imparcial capaz de elevarse sobre lo político. Por esto no es casual que en el plano de la participación social, los militares, usando fundamentalmente técnicas represivas y reformas legales, promovieran el 'orden' a través de la atomización y fragmentación del tejido social, buscando la obsecuencia y el disciplinamiento de la población.

Sin embargo, el disgusto de los militares por la política, particularmente por los partidos políticos, hizo difícil el proceso de institucionalización política y generalmente sus propuestas institucionales fallaron en proveer mecanismos eficaces de agregación de intereses e intermediación adecuados. En su conjunto, este escenario representó más bien la patética manifestación de una profunda desarticulación y atomización; los efectos desorganizadores de la matriz histórica de la sociedad, donde los militares no lograron configurar de manera estable modos diferentes de orden social, económico, cultural y político.

Así, en la práctica, las dictaduras militares fueron incapaces de proteger al Estado de la colonización de los poderes sociales y terminaron siendo víctimas del mismo tipo de politización que venían a combatir. La descripción que hace O’Donnell (1997) de las tensiones que constantemente permearon la alianza autoritaria desafía la noción del autoritarismo como un caso extremo de autonomía del Estado, en la cual el Estado reina majestuosamente sobre la sociedad. En realidad el 'Estado burocrático autoritario' demostró una similar fragilidad y una propensión a ser colonizado por los intereses privados que la asemejaba al Estado pretoriano que trataba de reemplazar. El asalto o autogolpes internos al Estado de grupos sociales particulares, que se apropiaron de sectores burocráticos específicos para alcanzar sus intereses privados, minó la racionalidad institucional del Estado burocrático autoritario (O’Donnell, 1997).

Tal que la privatización de las instituciones estatales contribuyó, como en el pasado, a la erosión, fragmentación y, finalmente, a la caída del autoritarismo burocrático. Sólo que en esta ocasión no hubo diques para contener la destructiva dinámica del pretorianismo, ya que los mismos militares habían sido víctimas de la politización; porque las instituciones estatales que eran indispensables para restaurar el orden, o no existían, o habían 
sido desmenuzadas y desintegradas por la máquina militar (O’Donnell, 1982).

Resulta evidente, entonces, que la privatización del sistema político por la represión militar o por los grupos corporativos a través del decretismo pueden desacoplar temporalmente al sistema político del ambiente social (desdiferenciar), pero sólo la legalidad es capaz de establecer estructuras institucionales autónomas y despolitizar las estructuras institucionales evitando el resurgimiento del clientelismo. En este sentido, toma importancia la perspectiva sistémica que considera que estos fenómenos pueden explicarse a partir de la debilidad en la afirmación de la forma de diferenciación funcional y su coexistencia con mecanismos de delimitación de la exclusión que operan de un modo particular; porque, qué duda cabe, acá los gobiernos no han sido de leyes sino de hombres, sean estos dictadores, caudillos, presidentes o bufones.

Ahora, si la clave para fortalecer al derecho, con facultades de operativizar las decisiones políticas, reside precisamente en la clara diferenciación entre política y derecho lo cierto es que, en la periferia de la sociedad, la debilidad operativa del sistema jurídico lo imposibilita para ejercer plenamente la facultad de canalizar las decisiones políticas, porque aunque éste exista como texto, en los hechos no funciona. De ahí que las formas de inclusión autoritaria o clientelar continúan reproduciendo las contradicciones sociales mediante violencia política organizada, economía informal o abierta corrupción política, toda vez que devienen en sustitutos funcionales de la modernidad en la modernidad y se transforman en impedimentos estructurales para una auténtica diferenciación funcional y operativa en las democracias de la región.

La frágil y precaria institucionalidad deviene condición suficiente para que allí actúen y se impongan lógicas de coordinación caudillistas o autoritarias y las diversas formas de regímenes clientelares se continúen unas a otras en una sucesión casi impredecible y desconcertante, toda vez que al no estar asociados con una forma de gobierno particular, pueden alternarse con regímenes cuasi democráticos y cuasi despóticos. Baste observar el caso de las recientes transiciones democráticas, donde una de las máximas complicaciones está dada por la existencia de un poder dual; el autoritario (que disminuye 'relativamente') y el 
democrático (que tiende a incrementarse, también 'relativamente'). ${ }^{35}$

Entonces, establecer el problema del régimen político como el criterio exclusivo del desarrollo político, sin contar con la institucionalidad requerida para cristalizar dicho proceso, más bien conduce a una teoría problemática de la institucionalización porque el aislamiento del sistema político del contexto social clientelar no es en sí suficiente. Las mismas instituciones deben ser despolitizadas, es decir, autonomizadas de intereses y poderes particulares, puesto que para institucionalizar una expectativa o consolidar la autonomía funcional de un sistema es irreducible desvincular la comunicación de todo compromiso inmediato, de toda valoración, condición necesaria que posibilita crear el orden característico en la sociedad moderna. De lo contrario, los caminos políticos hacia la construcción institucional siempre conspirarán contra la formación de instituciones autónomas, ya sea bajo las dictaduras militares (o regímenes autoritarios, como el caso de México) donde el Estado es colonizado por los intereses de los mismos militares, por sus aliados o por el caudillismo clientelar con su lógica líder-movimiento (Toledo en Perú, Chávez en Venezuela). ${ }^{36}$

Sólo la constitucionalización del poder del Estado completa el proceso de desacoplamiento de las instituciones del Estado de

${ }^{35}$ Vayamos de nuevo al caso chileno. Antes, durante y después del llamado proceso de transición democrática, los partidos políticos no han logrado superar la lógica movimiento-no-movimiento. Imposibilitados de recuperar la acción mediadora entre los intereses de la sociedad y el Estado, más bien operan como plataformas de líderes carismáticos que reproducen el modelo movimentista y clientelar, promoviendo una lógica de identidad social que está dada por el principio de la adscripción y no de adquisición, y ello en un escenario donde se da por supuesto que los partidos políticos deberían ser un mecanismo crucial en la institucionalización política, toda vez que éstos están equipados para institucionalizar la política como estructura de articulación y agregación de intereses. Los partidos, al tener un pie en el sistema estatal y otro en los diversos subsistemas de la sociedad, desde donde toman demandas, aspiraciones y cuadros para procesarlos en el marco de la lucha por el poder político, podrían lidiar más adecuadamente con los problemas presentados por la complejidad social (incertidumbre). Sin embargo, sus lógicas carismáticas terminan reactivando el modelo clientelar. Un trivial análisis sobre las gestión/instrumentación, en las municipalidades chilenas, de las políticas públicas destinadas a los sectores más vulnerables de la población devela la lógica clientelar que les subyace.

${ }^{36}$ Aunque en realidad el caso de Chávez ('El Chavismo') es mucho más complicado. Baste señalar que el actual mandatario recupera una orientación de tipo nacionalista liberal: siguiendo una política económica interna bastante ortodoxa al tiempo que ha impulsado una política exterior nacionalista e independiente; lo cual ha suscitado el antagonismo y la ira de Estados Unidos. Esto incluye su oposición al Plan Colombia, su crítica a la guerra de Estados Unidos en Afganistán y a la ofensiva imperial en el ámbito mundial, sus relaciones cordiales con Irak, Irán y Cuba, y su rechazo a permitir que Estados Unidos colonicen el espacio aéreo venezolano. 
fuerzas sociales particulares. Es sobre esta base que en las democracias consolidadas la ley tiene el consenso social suficiente y la institucionalidad requerida, de modo que se torna difícil, cuando no imposible, escapar de ella. De allí la importancia en insistir que cualquier forma de Estado autoritario no es soberana; el Estado soberano, en el sentido moderno del término, es el producto del establecimiento del imperio de la ley. A través de leyes generales el constitucionalismo elimina la pluralidad de privilegios medievales, ubicando al Estado como la institución política soberana.

En cambio, en América Latina, la ley es algo que el poderoso puede ignorar o regatear, situación que al normalizarse se convierte en expresión de la hipertrofia del sistema, pues bloquea la sensibilidad de los distintos subsistemas y reduce el poder de auto-inmunización del mismo. ${ }^{37}$

En consecuencia, es errado ver al constitucionalismo como un mero mecanismo de limitación del poder estatal. ${ }^{38}$ El constitucionalismo, es decir, la autonomía e imperio del derecho, crea y organiza el poder del Estado, despolitizando la política a través de la juridificación. Eso es lo que constituye al Estado legal moderno y, en este sentido, el constitucionalismo viene a fortalecer al Estado ya que lo constituye como una institución autónoma, separado de la miopía y el particularismo de fuerzas corporativas. Ya lo señalaba Schmitt: es el constitucionalismo el que da nacimiento al Estado legal moderno puesto que la juridificación del poder del Estado a través del derecho y la Constitución del Estado como institución representan dos caras de la misma moneda (véase Schmitt, 1982: 86).

Sólo la formación de un sistema institucional compatible con el grado de diferenciación social, característico de las modernas sociedades complejas, es capaz de establecer un complejo cons-

\footnotetext{
${ }^{37}$ Resulta evidente, entonces, que si el constitucionalismo emancipa las instituciones de la lógica política, garantizando su coherencia y autonomía institucional, un Estado legalmente constituido no puede depender de la voluntad del partido, de los militares, de la Iglesia, los poderes fácticos o de grupos corporativos, sino en las normas legales específicamente estipuladas que impiden, o dificultan, la colonización e instrumentalización de su aparato administrativo por parte de fuerzas particulares.

${ }^{38}$ Me señala un amigo chileno -cientista político- que el rescate del constitucionalismo y de la necesaria operatividad del derecho tienen, evidentemente, un marcado sello conservador, pues el constitucionalismo habría surgido para mantener el orden de dominación y la hegemonía, no sólo de aquellos que controlan el poder económico, sino también de los que producen la ley, las normas y las reglas que rigen a los sujetos en las sociedades democráticas iliberales (sic). Pregunté entonces, a mi revolucionario amigo, cuál es la forma para activar en los hechos las garantías y derechos de esos sujetos que a él tanto preocupan... aún no me responde.
} 
titucional efectivo, cuya base supone la total autonomía del derecho, de la política, de la ciencia, de la religión, etcétera.

Pero el bajo nivel en la construcción institucional de las sociedades latinoamericanas, íntimamente ligado a las formas asumidas en el proceso histórico de autoconstrucción de sus sociedades civiles y a la erosión de los acuerdos legales constitucionales por parte de formas populistas de auto-entendimiento, imposibilitan tal operación. Este déficit institucional, fuertemente conectado con la permanencia de formas políticas de autoentendimiento que erosionan la autoridad del constitucionalismo como institución, propicia y se imbrica, a su vez, con el surgimiento de movimientos populistas o autoritarios que, a través de la instrumentación de mecanismos constitucionales propios, socavan la autoridad de la ley y del derecho como institución; en ausencia de una institucionalización cognitiva, de una cultura política real y normativa, aunque la ley exista, puede no acatarse.

Insomma, de frente a la carencia de una efectiva complejidad constitucional, el derecho ha sido incapaz de cumplir sus funciones constitutivas o regulativas. La juridificación ha tendido, más bien, a establecer un proceso de desarrollo no diferenciado, signado por las dramáticas crisis autoritarias y clientelares que siguen generando recurrentes cuellos de botella en la historia política y social de la región. Así, con frágiles instituciones cognitivas y normativas, o en su ausencia, que establezcan y mantengan los límites sistémicos, es lógico que las dinámicas del cambio social asuman la forma de caóticos choques entre lógicas sectoriales desordenadas y una creciente politización no mediada; debilidad que explica, en parte y aún bajo regímenes democráticos funcionales, la carencia de derechos con aplicación universal.

Evidentemente, el éxito de las reglas y normas está intrínsecamente ligado a la institucionalización de un complejo constitucional efectivo, ya que en las sociedades modernas el principio de separación de poderes debe extenderse mas allá de la estabilización del dualismo política/sociedad hacia un papel más comprensivo, que posibilite mantener y coordinar una pluralidad diferenciada de lógicas institucionales. De lo contrario, cuando la plausibilidad de cualquier reforma resulta a priori demasiado incierta, toda vez que el futuro también se torna incierto, las estrategias de cooperación devienen improbables porque las negociaciones se hacen cada vez más difíciles y engorrosas al no estar sustentadas en instituciones que delimiten y puedan realmente 
dar salida a acuerdos, potenciando el círculo vicioso de la coordinación corporativa.

En otras palabras, se requiere de una clara conceptualización del papel del derecho y del constitucionalismo en la política de la consolidación democrática, para que los derechos fundamentales no sólo protejan al individuo del Estado; si no también posibiliten estructurar el ambiente de la burocracia con la intención de consolidar al Estado como un subsistema de la sociedad y hacer complexivamente plausible una actividad de comunicación más eficaz e influyente, toda vez que la institucionalidad cognitiva-normativa es el vínculo más importante del tejido democrático. Es decir, la institucionalidad referida a la estructura de los derechos, a las operaciones del sistema jurídico y a los aparatos que garantizan la reproducción sociocultural de la sociedad.

Pero al observar las dificultades de afirmación de la democracia en el continente, se hacen manifiestas las resistencias que se han sedimentado o estructurado en el paso de la estratificación a la diferenciación funcional y que han cobrado un peso significativo en el desarrollo de las delimitaciones territoriales realizadas con la formación de los Estados nacionales en la región. Resulta problemático, entonces, en sociedades periféricas orientadas por un orden centralizado, cuando la intervención de los sistemas periféricos por parte del sistema central corrompe la secuencia comunicativa, puesto que hace implausible la comprensión de una nueva comunicación ya que el sistema así intervenido no está motivado para comprender, sino tan solo para aceptar la intervención impuesta. Precisamente, sustitutos funcionales como el autoritarismo o caudillismo han desarrollado funciones de estabilización, en el sentido que vienen a reforzar los impedimentos a la diferenciación, estabilizando formas de desestabilización permanente de los códigos de funcionamiento en el sistema del derecho y de la política, los cuales alcanzan niveles de hipertrofia que serían, paradójicamente, inexplicables sin ellos. ${ }^{39}$

Ahora, no se trata tampoco de abogar sólo por la existencia de normas como fórmula mágica para resolver todos los problemas, ni tampoco, como de hecho sucede, valorar las reglas en sí mismas. Lógicamente, la pura existencia de reglas no asegura

\footnotetext{
${ }^{39}$ Quizá el desafió sea potenciar al conjunto de estas instituciones diferenciadas, las cuales, no obstante su imperfección, mantengan a los actores al interior de las reglas del juego democrático. De lo contrario, lejos de lograr las ansiadas metas de consolidación democrática y reforma del mercado, reactivarán el estéril patrón autoritario o clientelar.
} 
más que eso (la ley se acata, pero no se obedece), pero si en nuestro continente se quiere ir un paso más allá y dar cabida a los horizontes utópicos de sentido, es prioritario antes que nada que las reglas y normas básicas consagradas en las constituyentes sean efectivas. Es decir, que el Estado de derecho sea operativo y funcional para todos, puesto que la función más importante del derecho, a través de sus estructuras operativas (Poder Judicial), es ganar y conservar legitimidad mediante la solución de conflictos de la gente común, generando confianza. Entonces, a menos que concentremos nuestra atención en la cuestión ignorada de cómo hacer que el derecho funcione en las cosas más triviales, el Estado de derecho y la democracia nunca se consolidarán en América Latina.

Por último, insistir en la necesaria operatividad del derecho y del constitucionalismo, que es, al fin y al cabo, la carta magna que nos permite lo que debemos hacer, al mismo tiempo que nos prohíbe lo que no hay que hacer. $\mathrm{O}$, dicho en la semántica moderna, insistir en la funcionalidad y operatividad del derecho y de la institucionalidad, referida a la estructura de las operaciones del sistema jurídico y a los aparatos que garantizan la reproducción sociocultural de la sociedad, para que a fin de cuentas nuestra historia sociopolítica deje de ser contada por un idiota

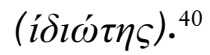

\section{Bibliografía}

Lomnitz, Larissa (1994), "Identidad nacional / cultura política: los casos de Chile y México", en Redes Sociales, Cultura y Poder: Ensayos de Antropología Latinoamericana, FLACso, Porrúa Editores, México.

Alberti, Giorgio (1997), La Construcción de la Democracia en América Latina, FLACSO, México.

Baraldi, Claudio (1996), Voz “diferenciación”, en G. Corsi, E. Esposito, C. Baraldi, Glosario sobre la teoría social de Niklas Lubmann, Anthropos, Universidad Iberoamericana, ITESo, México.

${ }^{40}$ En el sentido griego de la palabra: es decir, persona sin fundamentos. 
Castoriadis, Cornelius (2001), “¿Qué democracia?”, Figuras de lo pensable, Fondo de Cultura Económica, México.

Fernandes Campilongo, Celso (2000), O Direito na Sociedade Complexa, mimeo, PUc, Brasil.

Garretón, Manuel (1983), Institucionalización y Oposición al Régimen Militar: 1973-1980, FlACso, Santiago de Chile.

Hobsbawn, Eric (2002), "La guerra y la paz en el siglo xx", $L a$ Jornada, 24 de marzo, México.

Huntington, Samuel (1972), El Orden Político en las Sociedades en Cambio, Paidós, Barcelona.

Kosellek, Reinhart (1986), Futuro Passato. Per una semantica dei tempi storici, Casa Editrice Marietti S. p. A., Génova.

Langley, Lester D. (1996), The Americas in the Age of Revolution 1750-1850, Yale University Press, New Haven.

Leal, Antonio (1996), El crepúsculo de la política, Lom Ediciones, Santiago de Chile.

Lechner, Norbert (1995), Los Patios Interiores de la Democracia. Subjetividad y Politica, Fondo de Cultura Económica, México.

- (1997), “Tres formas de coordinación social”, Revista de la CEPAL núm. 61, Santiago, Chile.

Loveman, Brian (1993), The Constitution of Tyranny: Regimes of Exception in Spanish America, University of Pittsburgh Press, Pittsburgh.

Luhmann, Niklas (1973), Ilustración Sociológica, Sur, Buenos Aires.

- (1991), Sistemas Sociales: Lineamientos para una teoría general, Alianza Editorial, Universidad Iberoamericana, México. 
(1996), Confianza, Anthropos Editorial, Universidad Iberoamericana, Barcelona.

_- (1998), "Complejidad y democracia", Niklas Luhmann. Teoría de los sistemas sociales (artículos), Universidad Iberoamericana, México.

- (2001), La política de la sociedad, (traducción provisoria de Javier Torres Nafarrate), mimeo, Alemania.

—_ y Raffaele De Giorgi (1996), Teoria della società, Franco Angeli Editore, Milán.

Marshall, T. H. y Tom Bottomore (1998), Ciudadanía y clase social, Alianza Editorial, Madrid.

Mascareño, Aldo (2001), Teoría de sistemas de América Latina. Conceptos fundamentales para la descripción de una diferenciación funcional concéntrica, manuscrito, Santiago de Chile.

Moulian, Tomas (1997), Chile actual, anatomía de un mito, Editorial Lom, Santiago de Chile.

O’Donnell, Guillermo (1982), El Estado burocrático autoritario. Triunfos, derrotas y crisis, Editorial Belgrano, Buenos Aires.

_ (1997), "Delegative Democracy", Journal of Democracy núm. 5.

Sartori, Giovanni (1996), Ingeniería constitucional comparada. Una investigación de estructuras, incentivos y resultados, Fondo de Cultura Económica, México.

Schmitt, Karl (1982). Teoría de la Constitución, Alianza Universidad, Madrid.

Spencer-Brown, George (1979), The Laws of Form, E. P. Dutton, New York. 
Torres Nafarrete, Javier (1996), Introducción a la teoría de sistemas, Anthropos-Universidad Iberaomericana-ITESO, México.

Walder, Paul (2002), "Latinoamérica lucha contra sus viejos fantasmas”, <http://www. primeralínea.cl/>, 24 de marzo.

Whitehead, Laurence (1998), "State Organization in Latin America Since 1930", in Leslie Bethell (ed.), Latin American Economy and Society Since 1930, Cambridge University Press, Cambridge, 381-440.

Zamorano, Raúl (2001), "La democrazia dei postmoderni. Circa un gesto allegorico e metaforico" Rivista di Diritto e Cultura, Ed. ESI, Nápoles.

Zolo, Danilo (1997), “El léxico de Luhmann”, en Antonio Camou y José Esteban Castro (Comps.), La sociedad compleja: ensayos en torno a la obra de Niklas Lubmann, FLACSo-Triana Editores, México.

Enviado: 22 de abril de 2002. Reenviado: 2 de octubre de 2002. Reenviado: 21 de octubre de 2002. Aceptado: 18 de marzo de 2003. 
